\title{
Design of Parallel-Plate Transmission Line Feeding Differentially Driven Patch Antenna for GPS application
}

\author{
Krishna Mani Pandey ${ }^{1}$, Nitin Muchhal ${ }^{2}$, Kamal Niwaria ${ }^{3}$, Dr. Sunanda Manke ${ }^{4}$ \\ ${ }^{1}$ M.Tech Final year Student, Department of ECE \\ Barkatullah University Institute of Technology Bhopal \\ krishna_mani_pandey@yahoo.co.in \\ ${ }^{2}$ Associate Professor, Department of ECE \\ Sagar Institute of Science and Technology (SISTec), Bhopal India \\ n.muchhal@sistec.ac.in \\ ${ }^{3}$ M.Tech Final year Student, Department of ECE \\ Barkatullah University Institute of Technology Bhopal \\ ${ }^{4}$ Associate Professor, Department of ECE \\ Barkatullah University Institute of Technology Bhopal
}

\section{ABSTRACT}

\begin{abstract}
In this paper a newly developed patch antenna, designated as the parallel-plate transmission line feeding differentially driven patch antenna is presented. The parallel-plate transmission line will not introduce inductance to the input impedance of a patch antenna, thus the height of the patch can be largely increased. Measurements show that the 3-dBgain bandwidth can be obtained to $65 \%(0.86-1.93 \mathrm{GHz})$, return loss is $-20 \mathrm{~dB}$, VSWR is 1.3 and impedance is 51 ohm at resonant frequency of $1.58 \mathrm{GHz}$. The radiation pattern is stable and this antenna is designed for GPS application.
\end{abstract}

\section{INDEX TERMS}

3-dB-gain bandwidth, Differentially driven antenna, bandwidth, parallel-plate transmission line, CADFEKO.

\section{Council for Innovative Research}

Peer Review Research Publishing System

Journal: INTERNATIONAL JOURNAL OF COMPUTERS \& TECHNOLOGY

Vol 12, No.4

editor@cirworld.com

www.cirworld.com, member.cirworld.com 


\section{INTRODUCTION}

In Recent years, differential circuits are becoming more popular in microwave circuit design, due to their good performances such as low noise, harmonic suppression, high linearity, and large dynamic range. Thus they can be used in radio frequency integrated circuits (RFICs) and microwave monolithic integrated circuits (MMICs) [1] [2]. However, most antennas are designed for single-ended circuits. Baluns are required to transform differential signals to single-ended signals, when they are integrated with differential circuits. Thus, differentially driven antennas are demanded in differential microwave circuit designs to get rid of bulky off-chip and lossy on-chip baluns to improve the receiver noise performance or transmitter power efficiency. Moreover, the cancellation mechanism introduced by the differentially driven scheme largely reduces the cross-polarization radiation and thus enhances the polarization purity of the antenna [1] [3] [6].

Stable radiation and Wide gain bandwidths are the most demanded features for patch antennas. The easiest way to enhance the 3-dB bandwidth is to increase the height of the patch above the ground plane. However, because of the inductance introduced by the feeding structure, the height of the patch has to be limited within a few percent of a wavelength. For coaxial probe feeding, the height of the probe has to be increased with the height of the patch, which introduces extra inductance to the input impedance and deteriorates the input matching of the antenna. This effect limits the bandwidth of patch antennas [8].

A numerical study of newly developed patch antenna, designated as the parallel plate transmission line feeding differentially driven patch antenna has been presented. The parallel plate transmission line will not introduce inductance to the input impedance of the patch antenna, thus the height of the patch can be largely increased.

\section{ANTENNA DESIGN}

\section{A. Electrical Parameters of Differentially Driven Antenna}

For symmetric differentially Driven patch antenna, the differential input impedance $Z_{d}$ is given by [5]

$$
Z_{d}=Z_{11}-Z_{12}-Z_{21}-Z_{22}
$$

Where $\mathrm{Z} 11, \mathrm{Z} 12, \mathrm{Z} 21$ and $\mathrm{Z}_{22}$ are Z-parameters of two input ports when the differentially driven antenna is regarded as a two port single-ended network. The frequency at which the reactance of the input impedance $Z_{d}$ is equal to zero is known as resonant frequency [5]. From (1), we achieve the following relation as:

$$
\mathrm{S}_{\mathrm{d} 11}=1\left(\mathrm{~S}_{11}-\mathrm{S}_{12}-\mathrm{S}_{21}-\mathrm{S}_{22}\right) / 2
$$

Where $S_{d 11}$ is the reflection coefficient of differentially driven antenna. $S_{11}, S 12, S 21$ and $S_{22}$ are S-parameters of two input ports when the differentially driven antenna is regarded as a two port single-ended network. In this paper, the 3-dB gain bandwidth of the differentially driven patch antenna is defined as a range of frequencies over which the differential

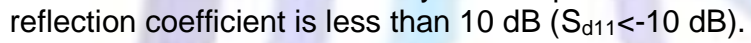

\section{B. Antenna Design}

The basic structure of the proposed antennas consists of a ground plane, a parallel-plate transmission line formed by two parallel plates, and a radiation patch. For conventional single ended probe feeding, the series inductance introduced by the probe is from the self-inductance of the probe. The longer the probe is, the larger the inductance will be introduced. This deteriorates the input matching of the antenna. On the other hand, the connection between the parallel plate and other parts of the antenna will also introduce a reactive component to the input impedance. However, according to the transmission line theory, series distributed inductance and shunt distributed capacitance make the parallel plate becomes a transmission line. From the microwave network theory, we know that the transmission line itself does not introduce a reactive component, but only changes the phase of signals. Thus, no matter how long it is, the parallel plate will not introduce extra inductance to the input impedance. By this way, the height of the patch fed by the parallel plate can be largely increased. Two lower edges of the parallel-plate transmission line are connected to two short feeding probes of two 50ohm SMA launchers. The characteristic impedance of the differential feeding line, thus, is $100 \mathrm{ohm}$. The short feeding probes are inevitable, but will only introduce small inductance to the input impedance of the antenna. The two SMA ports below the ground, together, are designated as the "differential input port" of the differentially driven patch antenna in [1].

For the antennas proposed in this paper, the ground plane is made with the thickness of $2 \mathrm{~mm}$. The radiation patch and parallel-plate transmission line are made with the thickness of $0.3 \mathrm{~mm}$. The radii of the two probes are $0.025 \mathrm{~mm}$. First, the parallel-plate transmission line is used to feed the radiation patch directly. This means the two higher edges of the parallel plate are connected to the bottom of the patch. Thus, electromagnetic (EM) energy can be transmitted from the parallel plate to the patch directly 


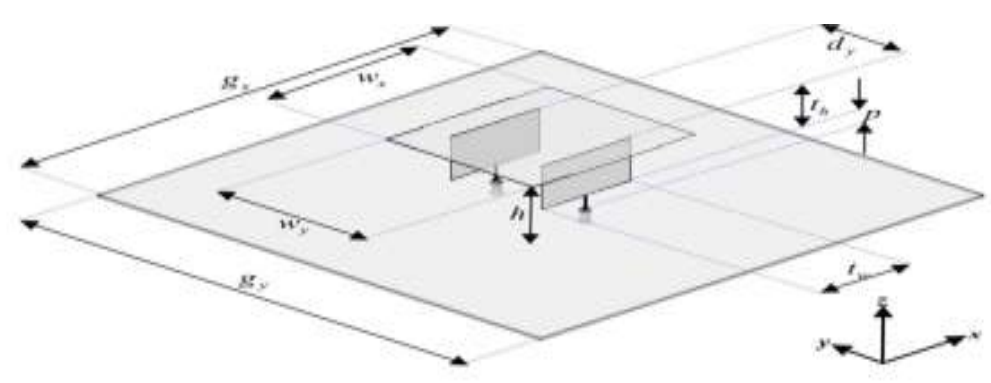

Fig.1 Geometry of Parallel-Plate transmission line, direct-feeding differentially driven patch antenna.

The geometry of the first antenna is shown in Fig. 1, where optimized geometrical parameters of the antenna are also given as shown in table 1.

Table 1

\begin{tabular}{|l|l|l|l|l|l|l|l|l|}
\hline Parameter & $g_{x}=g_{y}$ & $t_{w}$ & $t_{h}$ & $p$ & $h$ & $d_{y}$ & $w_{y}$ & $w_{x}$ \\
\hline Value $(\mathrm{mm})$ & 300 & 74 & 32.5 & 5.5 & 38 & 30 & 100 & 110 \\
\hline
\end{tabular}

The simulation process has been done through FEKO electromagnetic software which is based on method of movement (MOM). The optimization is done through FEKO simulation software. It was used for optimizing electromagnetic problems. The optimized antennas were determined to have desired resonant frequencies, high gain, and low weight return losses.

The radiation patch is placed over a ground at the height of $38 \mathrm{~mm}$.

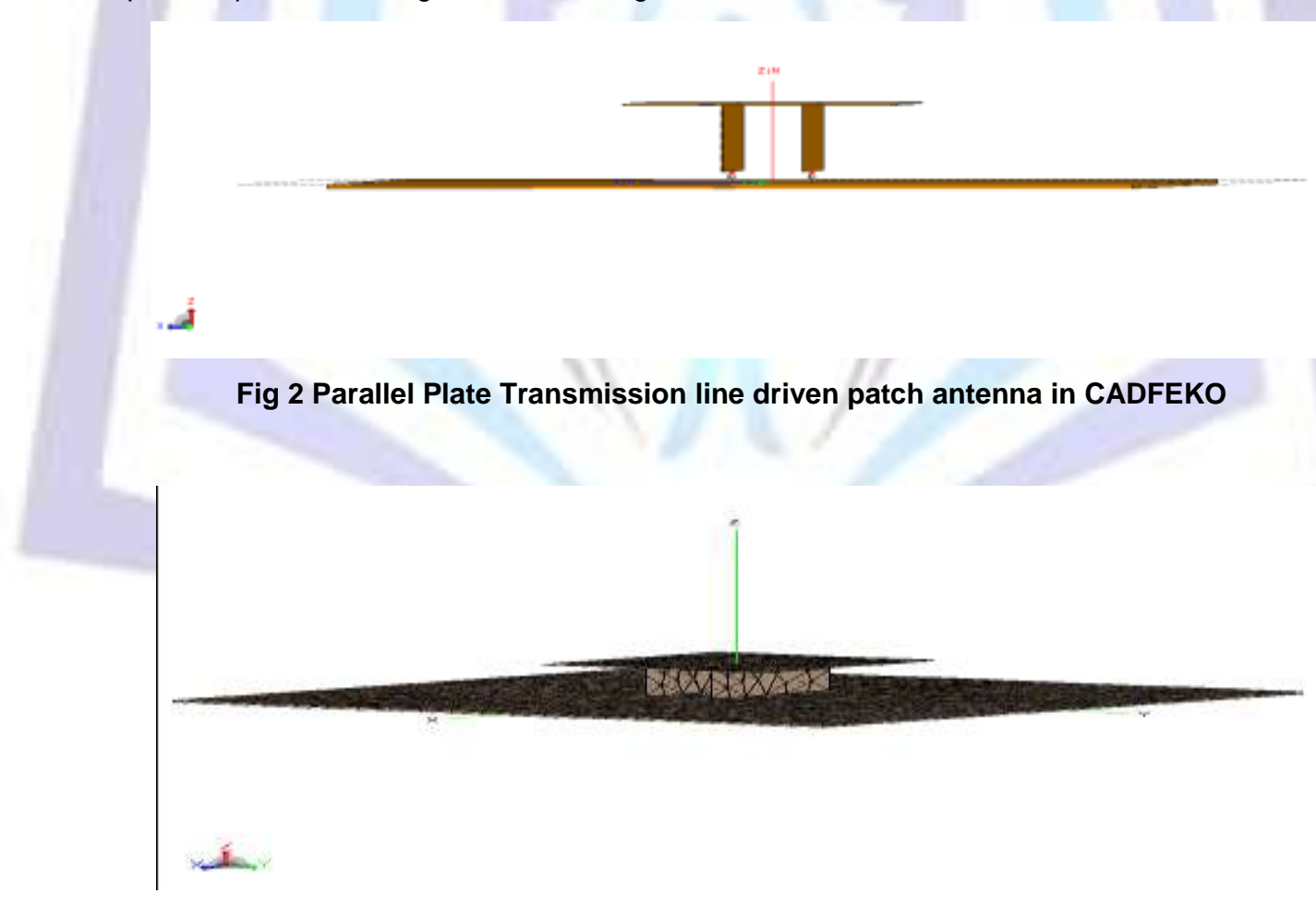

Fig 3 Parallel Plate Transmission line driven patch antenna in POSTFEKO

\section{RESULTS AND ANALYSIS}

The simulation process has been done through FEKO electromagnetic software which is based on method of movement (MOM). The 3-dB-gain bandwidth is $65 \%(0.86-1.93 \mathrm{GHz})$. It can be observed that the proposed antenna has a Return loss of $-20 \mathrm{Db}, \mathrm{VSWR}$ is less than 2 and impedance is 51 ohmat the resonant frequency of $1.58 \mathrm{GHz}$. It is noted that the resonances occurs at $1.58 \mathrm{GHz}$. 


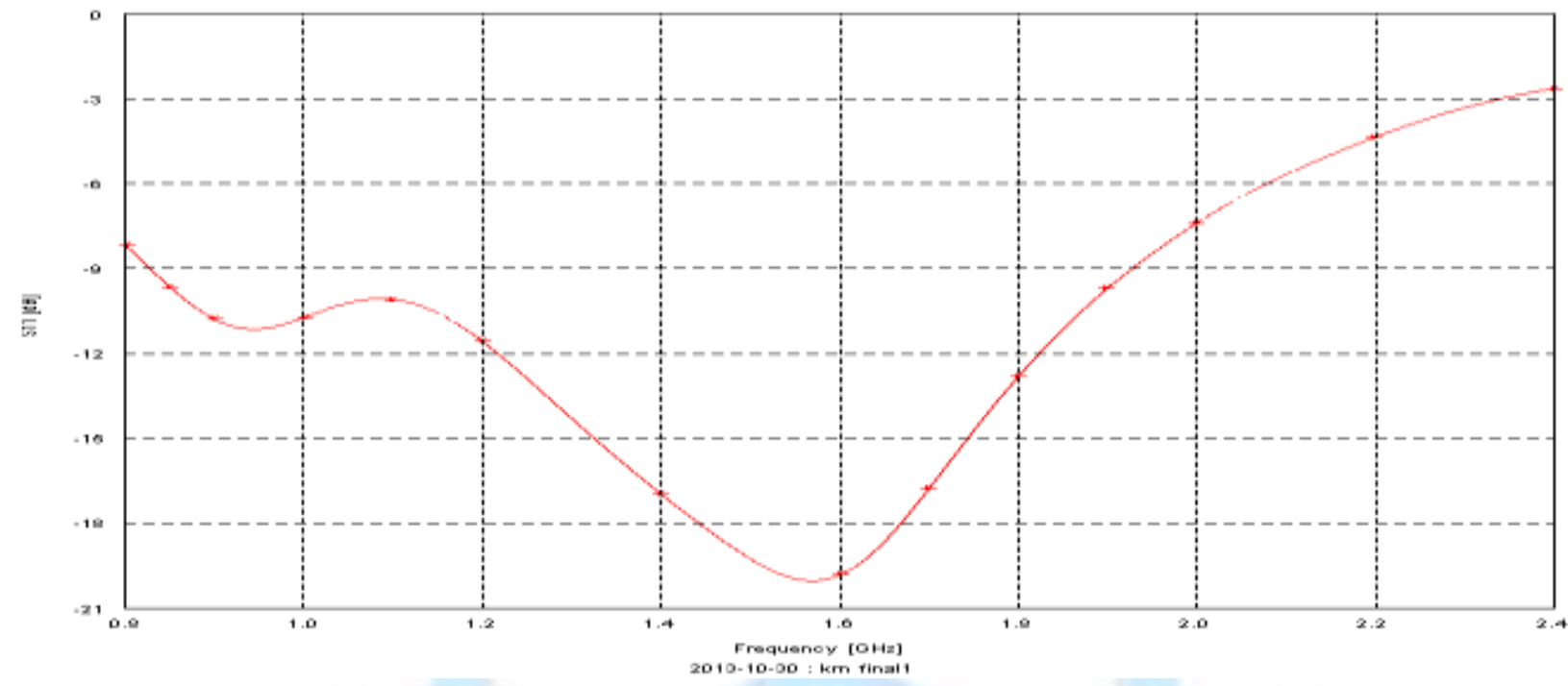

Fig 4 Return loss vs frequency

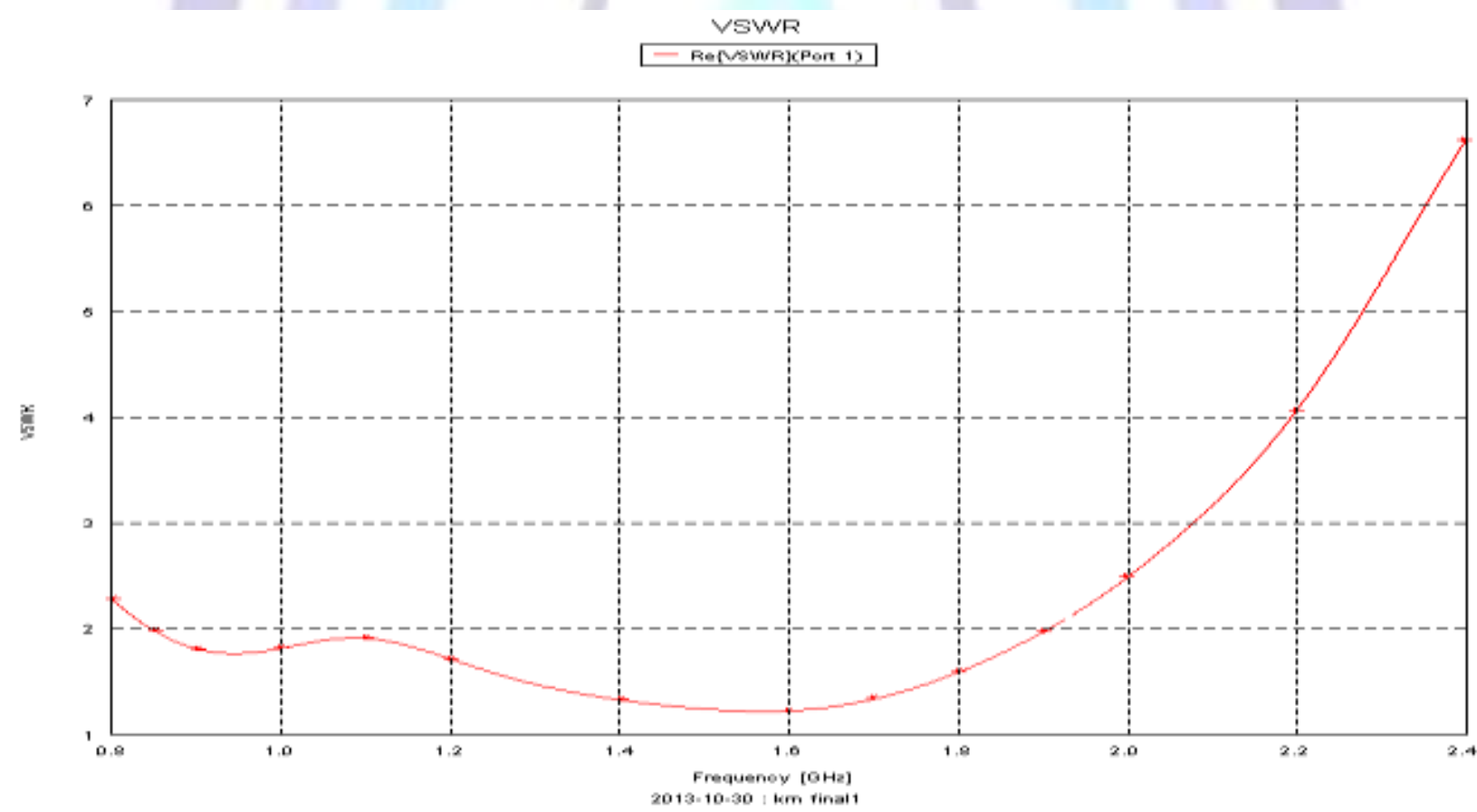

Fig 5 VSWR vs frequency 

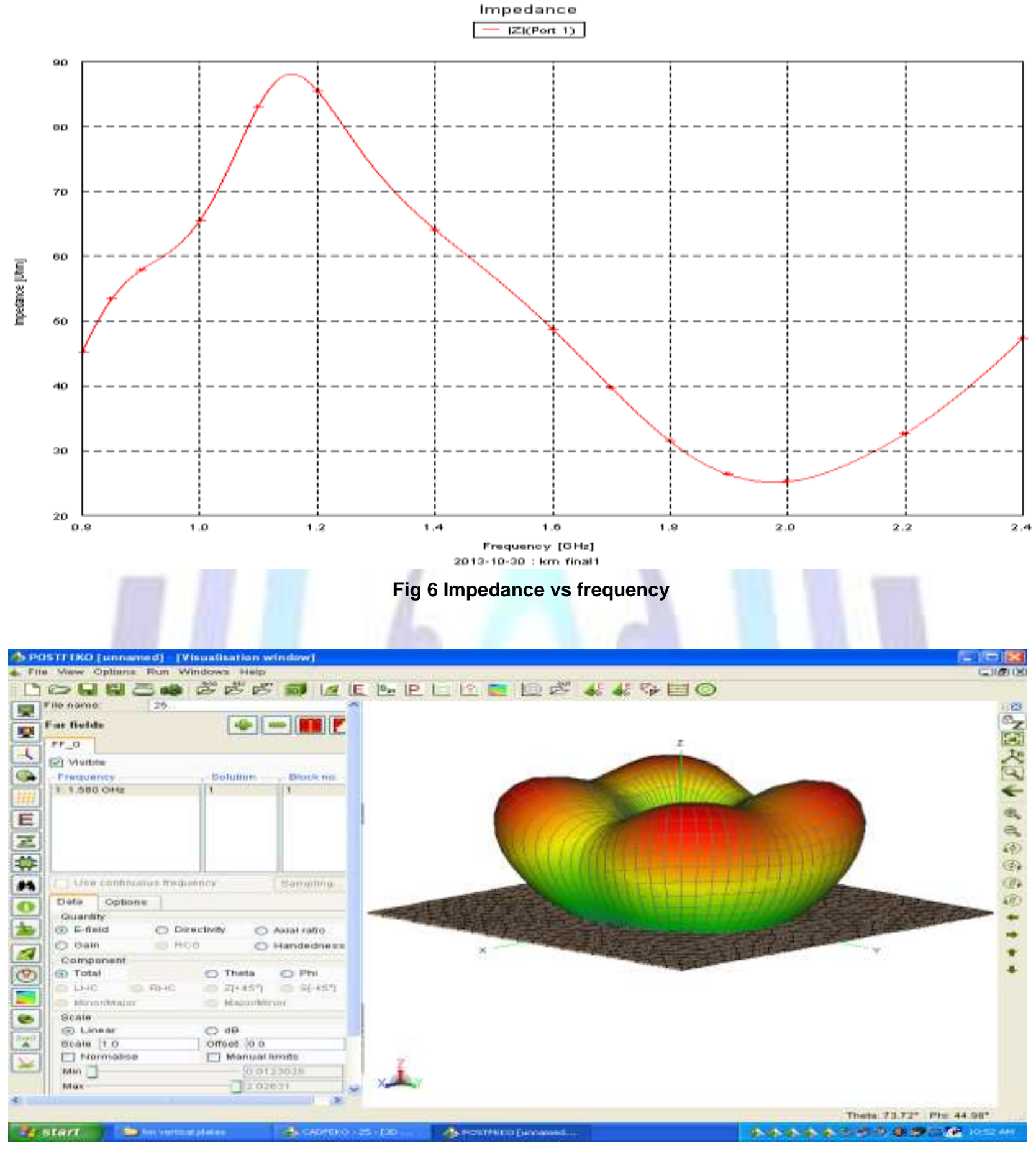

Fig7 3-D view of Radiation Pattern

\section{CONCLUSION}

A newly developed single-patch antenna, called parallel-plate transmission line feeding differentially driven patch antenna, has been designed and implemented successfully. The measured results demonstrated that it has a wide 3-dB-gain bandwidth of $65 \%(0.86-1.93 \mathrm{GHz})$, return loss is $-20 \mathrm{~dB}, \mathrm{VSWR}$ is 1.3 and impedance is 51 ohm at resonant frequency of $1.58 \mathrm{GHz}$. The radiation pattern is stable within the $3-\mathrm{dB}$-gain bandwidth. Due to the symmetry of the structure and excitation, the radiation pattern is symmetric about both E-plane and $\mathrm{H}$-plane. Due to its wide bandwidth, a possible application of the proposed antenna is that it can be used as a base-station antenna, simultaneously providing different wireless access services, e.g. GPS application. 


\section{REFERENCES}

[1] Shao Wei Liao, Quan Xue, Fellow, IEEE, and Jian Hua XuW, Parallel-Plate Transmission Line and L-Plate Feeding Differentially Driven H-Slot Patch Antenna ,IEEE Antennas and Wireless Propagation Letters, VOL. 11, 2012.

[2] W. R. Eisenstadt, B. Stengel, and B. M. Thompson, Microwave Differential Circuit Design Using Mixed-Mode SParameters. Boston, MA: Artech House, 2006, pp. 1-25.

[3] A. R. Behzad, M. S. Zhong, S. B. Anand, L. Li, K. A. Carter, M. S. Kappes, T. H. Lin, T. Nguyen, D. Yuan, S. Wu, Y. C. Wong, V. Gong, and A. Rofougaran, "A 5-GHz direct-conversion CMOS transceiver utilizing automatic frequency control for the IEEE 802.11 a wireless LAN standard," IEEE J. Solid-State Circuits, vol. 38, no. 12, pp. 2209-2220, Dec. 2003.

[4] Y. P. Zhang, "Design and experiment on differentially-driven microstrip antennas," IEEE Trans. Antennas Propag., vol. 55, no. 10, pp. 2701-2708, Oct. 2007.

[5] Y. P. Zhang and J. J. Wang, "Theory and analysis of differentially driven microstrip antennas," IEEE Trans. Antennas Propag., vol. 54, no. 4, pp. 1092-1099, Apr. 2006.

[6] Q. Xue, X.Y.Zhang, and C.H.K.Chin, "A novel differential-fed patch antenna," IEEE Antennas Wireless Propag. Lett. vol. 5, pp. 471-473, 2006.

[7] C. H. Chin, Q. Xue, and H. Wong, "Broadband patch antenna with a folded plate pairas a differential feeding scheme," IEEE Trans. Antennas Propag., vol. 55, no. 9, pp. 2461-2467, Sep. 2007.

[8] P. Li, K. L. Lau, and K. M. Luk, "A study of the wide-band probe fed planar patch antenna mounted on a cylindrical or conical surface," IEEE Trans. Antennas Propag., vol. 53, no. 10, pp. 3385-3385, Oct. 2005.

[9] H. W. Lai and K. M. Luk, "Design and study of wide-band patch antenna fed by meandering probe," IEEE Trans. Antennas Propag., vol. 54, no. 2, pp. 564-571, Feb. 2006.

[10] K. F. Lee, S. L. S. Yang, A. A. Kishk, and K. M. Luk, "The versatile U-slot patch antenna," IEEE Antennas Propag. Mag., vol. 52, no. 1, pp. 25-39, Feb. 2010.

[11] A. C. Lepage and X. Begaud, "A compact ultra wideband triangular patch antenna," Microw.Opt. Technol. Lett., vol. 40, pp. 287-289, 2004.

[12]. Y. X. Guo, C. L. Mak, K. M. Luk, and K. F. Lee, "Analysis and design of L-probe proximity fed-patch antennas," IEEE Trans. Antennas Propag., vol. 49, no. 2, pp. 145-149, Feb. 2001. 